\title{
A New Application of the Severity Factor Kinetic Model: Thermal Plasma Treatment of Black Liquor
}

\author{
Viviane Yargeau, Bernard Marcos and Gervais Soucy*
}

\author{
Department of Chemical Engineering, Université de Sherbrooke, QC, Canada J1K 2R1
}

S everal major industries, such as the Pulp and Paper and the Aluminium manufacturing industries, experience problems with the treatment of caustic solutions used in their processes. The black liquor solution, produced during the cooking of wood, is a good example of such a solution. The reaction kinetics involved in the treatment of black liquor through the conventional recovery boiler are not fully understood. Furthermore, the processing bottleneck for many pulp production plants is the boiler plant used to recover and recycle the caustic solution. Better kinetic prediction tools would be beneficial for the optimization of this current treatment and in the development of new treatment technologies such as the submerged plasma treatment system.

The overall kinetics approach is the simplest model for kinetic behavior (Cusack, 1999), but it yields poor results for more complex systems. In fact, a preliminary analysis of results obtained under various operating conditions (pressure, organics, sulfur and catalyst concentrations and plasma gas) indicates that the overall reaction order is changing with respect to operating conditions. As an example, Figure 1 illustrates the variation of the overall reaction kinetics order for sulfur oxidation with respect to previously mentioned operating conditions. On the other hand, a detailed model of the kinetic behavior can be developed by taking a mechanistic approach (Westbrook and Dryer, 1984) but the complete reaction mechanism must be known in order to formulate the model. However, the reaction mechanism of the complex system, formed during thermal treatment of black liquor, remains unknown. Between these two approaches lies the phenomenological approach that has given rise to the severity factor kinetic model for the complex system of the decomposition of the lignocellulosics fractionation (Abatzoglou et al., 1992) and (Montané et al., 1998).

The main objective of the study related in this paper has been the development of a better prediction tool for the kinetic behavior of the caustic solution components, based on the severity factor kinetic model, in order to optimize the operating conditions for thermal treatment of the complex chemical system formed by the black liquor. The information so obtained is potentially useful for conventional recovery boiler optimization and for the development of innovative submerged plasma technology as a make-up system to incrementally increase black liquor treatment capacity of the pulp and paper industry. This paper presents the severity factor kinetic model, a synthetic solution being used as a surrogate for the black liquor and the set-up used to obtain experimental data for the identification of the model's parameters and its validation. The factorial analysis results are then used in the discussion of this

\footnotetext{
* Author to whom correspondence may be addressed. E-mail address: gervais.soucy@usherbrooke.ca
}

\begin{abstract}
The kinetic analysis of the treatment of black liquor by a thermal process can be performed in the conventional overall kinetic approach. However, while the detailed reaction mechanism remains unknown, the experimental analysis of black liquor treatment by submerged plasma demonstrates that the operating conditions (catalyst, plasma gas, temperature...) modify the kinetics and render this approach inefficient. The phenomenological approach based on the severity factor developed for the kinetic analysis of lignocellulose decomposition, is then proposed as an alternative to the conventional approach. The 3-parameters model is validated for decomposition of formic acid and for sulfur oxidation.
\end{abstract}

\begin{abstract}
L'analyse cinétique du traitement thermique de liqueur noire s'effectue de manière conventionnelle par une approche de cinétique apparente. Toutefois, bien que le mécanisme réactionnel soit toujours méconnu, l'analyse expérimentale du traitement de la liqueur noire par plasma submergé démontre que les conditions d'opération (catalyseur, gaz plasmagène, température...) modifient suffisamment la cinétique du système pour rendre cette approche globale inefficace. L'approche phénoménologique par facteur de sévérité, développée pour l'analyse cinétique de la décomposition de la lignocellulose, est donc proposée comme alternative. Le modèle, composé de trois paramètres, est validé pour la décomposition de I'acide formique et pour l'oxydation du soufre.
\end{abstract}

Keywords: severity factor, kinetics, phenomenological models, black liquor, submerged plasma, thermal treatment.

new application of the phenomenological severity factor kinetic model.

\section{Severity Factor Kinetic model}

\section{Model development}

The severity factor kinetic model, as applied to lignocellulosics fractionation, demonstrates that it is possible to predict the kinetic behavior of such a complex system through the use of a severity factor; this being a descriptor of the importance of operating conditions on 


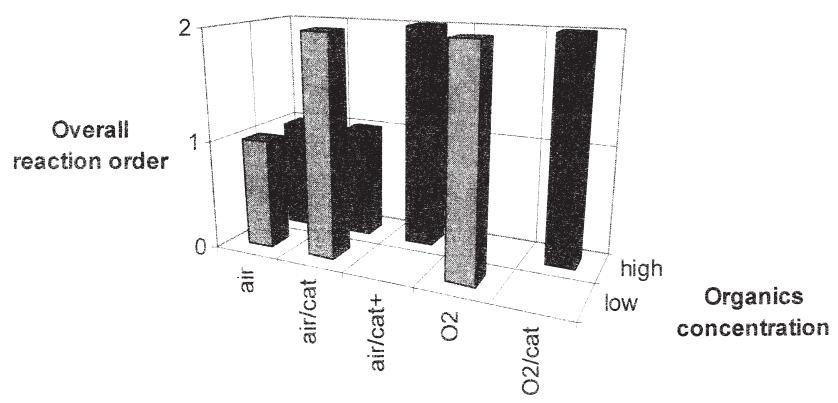

Figure 1. Influence of operating conditions on the global reaction order of sulfur oxidation.

the extent of conversion of the input material into products. The phenomenological severity factor is defined as the parametric combination of system temperature and reaction time, which is used in the parametric conversion equation involving catalyst concentration. These system conditions are related to each other through three parameters: $\gamma$, a parameter defining the shape of the Kohlrausch relaxation function and the shape of the activation energies distribution; $k_{\text {Tref }}$ Cref' the rate constant; and $m$, the reaction order for the catalyst. The model is also based on two reference conditions: the temperature and the catalyst concentration, as discussed later.

The phenomenological approach to kinetic analysis was first introduced by Geniesse and Reuter (1930), Brash and Free (1965) and Whitehurst (1980). In 1990, Montané, Overend and Chornet revised the earlier literature and proposed the use of the severity factor for combining the effect of temperature and residence time. In 1992, Abatzoglou et al., unified these two approaches and introduced the catalyst effect into the severity factor kinetic model. From the hypotheses set out below and the mathematical development of Montané et al. (1998), the severity factor is defined as a function of the system temperature, the reaction time and the activation energy distribution parameter, as follows:

$R_{0}=\exp \left(\frac{1}{\omega_{0}}\left(1-\frac{T_{r e f}}{T}\right)\right) \frac{t^{\gamma}}{\gamma}$

The conversion is then expressed as a function of the severity factor, the rate constant parameter, the catalyst concentration and the reaction order parameter, by means of the following equation:

$\ln (1-f)=k_{\text {Tref }, \text { Cref }}\left(\frac{C}{C_{\text {ref }}}\right)^{m} R_{0}$

Through mathematical manipulations of these two equations and the experimental data processing presented later, parameters can be identified and the model validated for the high temperature caustic solution treatment studied.

\section{Hypothetical Basis of the Model}

Modeling of the system conversion as a function of the severity factor, leading to the simplified Equations (1) and (2), has been approached with the following assumptions:
1. Reaction rate doubles for a specified temperature increment:

$\frac{r_{T}}{r_{\text {Tref }}}=\exp \left(\frac{T-T_{\text {ief }}}{\omega}\right)$

2. Specified temperature increment, for which the reaction rate doubles, is constant with respect to the conversion;

3. Reaction rate is independent of the conversion;

4. Process is irreversible and isothermal (temperature of the solution remains constant at steady state);

5. Catalyst concentration does not change significantly with time.

Parameters $\gamma, k_{\text {Tref, }}$ Cref

To determine the parameters $\gamma, k_{\text {Treft }}$ Cref of the model from experimental data, Equations (1) and (2) are combined to obtain:

$\ln (1-f)=-k_{\text {Tref }, \text { Cref }}\left(\frac{C}{C_{\text {ref }}}\right)^{m} \frac{t^{\gamma}}{\gamma} \exp \left(\frac{1}{\omega_{0}}\left(1-\frac{T_{\text {ref }}}{T}\right)\right)$

Substituting Equation (5) in Equation (4)

$\omega_{0} T=\frac{R T_{\text {ref }}}{E} T=\omega$

Equation (4) may be written as:

$\ln (1-f)=-k_{\text {Tref }, C r e f}\left(\frac{C}{C_{\text {ref }}}\right)^{m} \frac{t^{\gamma}}{\gamma} \exp \left(\frac{T-T_{\text {ref }}}{\omega}\right)$

Substituting Equation (7) in Equation (6)

$C=C_{\text {ref }}$

Equation (6) can be simplified as :

$\ln (1-f)=-k_{\text {Tref }, \text { Cref }} \frac{t^{\gamma}}{\gamma} \exp \left(\frac{T-T_{\text {ief }}}{\omega}\right)$

Taking the In of Equation (8) yields the following equation:

$\ln (-\ln (1-f))=\ln \left(\frac{k_{\text {Tref, Cref }}}{\gamma} \exp \left(\frac{T-T_{\text {ref }}}{\omega}\right)\right)+\gamma \ln t$

from which in the coordinate $(\ln (-\ln (1-f)$ versus $\ln t)$ the gamma parameter is the slope, and the rate constant parameter is a function of the $y$-intercept, $b$ :

$$
k_{\text {Tref,Cref }}=\gamma \exp \left[b-\frac{T-T_{\text {ref }}}{\omega}\right]
$$

\section{Parameter $m$}

To determine the parameter of the model from experimental data, logarithms are taking for Equation (6) : 


$$
\ln (-\ln (1-\mathrm{f}))=\left(k_{\text {Tref, }} \text { Cref } \frac{t^{\gamma}}{\gamma} \exp \left(\frac{T-T_{\text {ref }}}{\omega}\right)\right)+m \frac{C}{C_{\text {ref }}}
$$

In linearizing the catalyst contribution term through a series expansion around $C_{\text {ref }}$ truncated to the first term assuming that $C$ is close to $C_{\text {ref }}{ }^{\circ}$

$m \ln \left(\frac{C}{C_{\text {ref }}}\right) \approx m \frac{\left(C-C_{\text {ref }}\right)}{C_{\text {ref }}}$

Equation (11) can be written as-:

$\ln (-\ln (1-f))=\ln \left(\begin{array}{l}\frac{k_{\text {Tref, } \text {, ref }}}{\gamma} \exp \left(\frac{T-T_{\text {ref }}}{\omega}\right) \\ \exp \left(\frac{m\left(C-C_{\text {ref }}\right)}{C_{\text {ref }}}\right)\end{array}\right)+\gamma \ln (t)$

from which the parameter $m$ may be estimated from the $y$ intercept, $b$ and the following equation:

$m=\frac{C_{\text {ref }}\left\lfloor\omega\left(\ln \gamma-\ln k_{\text {ref, }, \text { Tref }}\right)+\omega^{*} b+T_{\text {ref }}-T\right\rfloor}{\omega\left(C-C_{\text {ref }}\right)}$

\section{Reference Conditions}

The severity factor kinetic model is based on two reference conditions: temperature and catalyst concentration. The reference temperature is needed for the calculation of the severity factor $R_{0}$, as stated in Equation (1), and for the identification of the rate constant used in the conversion relation to the severity factor, as expressed in Equation (2). A reference temperature of $25^{\circ} \mathrm{C}$ (298K) is chosen since no significant reaction (sulfur oxidation or organic acids decomposition) occurs at this temperature during the time period considered.

A reference catalyst concentration is also used in the conversion equation of the severity factor model, as expressed in Equation (2). Since reactions occur in the heated system even without catalyst influence, the catalyst concentration, expressed in volumetric units, is chosen to lie midway in the interval of catalyst concentrations studied, at a value of 0.033 $\mathrm{ml} / \mathrm{L}$. The choice of $T_{\text {ref }}$ and $C_{\text {ret }}$ does not have a significant effect on the optimal values for the parameters of the model (Montané et al., 1998).

\section{Experimental}

\section{Submerged Plasma Technology}

The technology used during this study to obtain kinetic experimental data, shown in Figure 2, is based on a submerged plasma system designed for fluids treatment (US Patent 6187 206 B1: February 13, 2001 and Patent Cooperation Treaty (PCT) WO9722556: December 20, 1996) adapted for this study, as previously described in (Yargeau et al., 2001) and (Yargeau, 2002).

The solution to be treated (1) is pumped (2) into the reactor (3) prior to plasma ignition. To place thermal energy in direct contact with the solution under treatment, a thermal plasma generated by a $45 \mathrm{~kW} \mathrm{DC}$ plasma torch (4) is submerged in the solution, at the bottom of the reactor. The

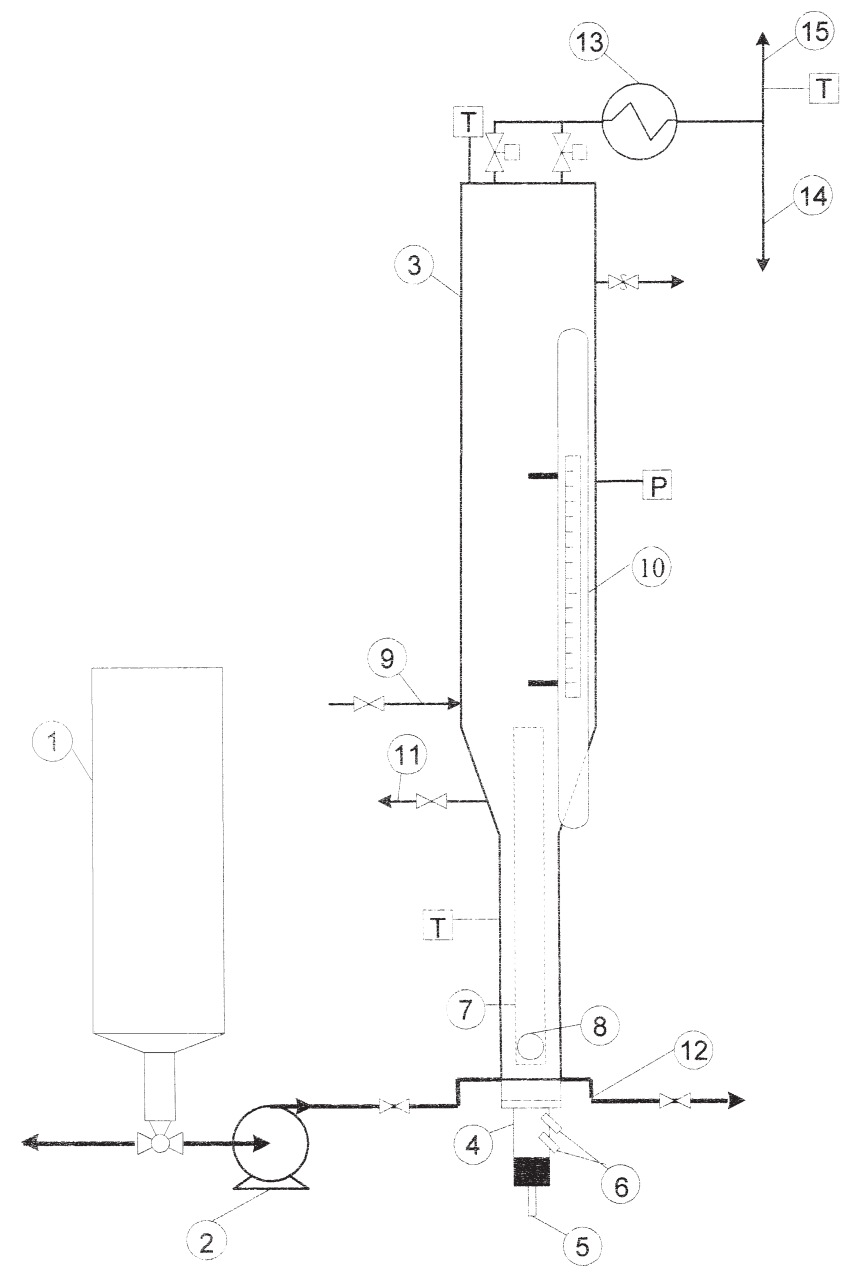

Figure 2. Experimental set-up.

Table 1. Concentration levels of the synthetic black liquor solution.

\begin{tabular}{lcccc}
\hline Species & Concentration Units & Level 1 & & Level 2 \\
\hline $\mathrm{NaOH}$ & $\mathrm{mol} / \mathrm{L}$ & & 0.23 & \\
$\mathrm{Na}_{2} \mathrm{CO}_{3}$ & $\mathrm{~mol} / \mathrm{L}$ & & 0.13 & \\
$\mathrm{HCOOH}$ & $\mathrm{mol} / \mathrm{L}$ & 0.14 & & 0.28 \\
$\mathrm{CH}_{3} \mathrm{COOH}$ & $\mathrm{mol} / \mathrm{L}$ & 0.07 & & 0.14 \\
$\mathrm{Na}_{2} \mathrm{~S}$ & $\mathrm{~mol} / \mathrm{L}$ & 0.07 & 0.14 \\
Lignin* $^{*}$ & $\mathrm{~g} / \mathrm{L}$ & 0 & 15 \\
\hline
\end{tabular}

* The type of lignin used is Indulin AT DB17 from Westvaco Corp Charleston, SC, USA

torch, fed with plasma gas (5) is cooled by tap water (6). To control both the liquid and the gaseous flow patterns in the reactor and to obtain adequate contact between the gas and liquid phase, a draft tube (7) is placed in a concentric position above the torch. Suitable configurations of the draft tube have been studied and optimized in the past (Quintal, 2001). Visual observations of the treatment in progress are possible through the porthole (8). During reactor operation, make-up water is added, using the reservoir (1) or a tap water line (9), at a 
flow rate known to keep the solution volume constant at 15 L. Under proper foaming control, the volume level is verified by use of the magnetic indicator located in a side tube (10). Treatment is carried out under pressure $(445 \mathrm{kPa})$ to reduce foaming problems and to increase the operating temperature (boiling temperature of the system). Liquid samples are taken through the sampling line located at the half-height level of the reactor (11), the reactor being drained by a line installed at the base (12) while gases leaving the reactor at the top are cooled by heat exchangers (13). The condensate from the gases is recuperated in a reservoir (14) and the cooled gases are sampled and sent to a scrubber (15) before exhausting to atmosphere.

\section{Black Liquor Solution}

To streamline the chemical analysis of the samples and to focus the analysis on the major compounds of the caustic solution identified by a literature review, a synthetic solution is used as a surrogate for the black liquor in most of the experimental runs. The use of this synthetic solution is also required by the characterization techniques limitations. The compounds introduced into the test solution, along with the composition range studied, are described in Table 1 . The various solution compositions are used in a factorial analysis, presented in the following section, to evaluate the influence of the concentration of some components on the treatment process and on the kinetic parameters of the severity factor model. For each experimental run, some fifteen liters of solution are prepared and processed in the submerged plasma system.

\section{Sample Analysis \\ Liquids}

During each 20-minutes treatment, liquid samples are taken from the reactor just above the reactor elbow (see \#11sampling line on Figure 2) at various time intervals: 0, 3, 8, 13, and 20 minutes. Samples are analyzed for most of the anions by ionic chromatography, using methods based on TAPPI standard methods, T699 om-87:
- $\mathrm{SO}_{3}{ }^{2-}, \mathrm{SO}_{4}{ }^{2-}, \mathrm{S}_{2} \mathrm{O}_{3}{ }^{2-}$

$>$ Ionic chromatograph: HPLC DX-500 with gradient pump -Analytical column:

AS11 4mm

>Eluent:

$\mathrm{Na}_{2} \mathrm{CO}_{3}, \mathrm{NaOH}$ and p-cyanophenol

- $\mathrm{HCOO}^{-}, \mathrm{CH}_{3} \mathrm{COO}^{-}$

$>$ Ionic chromatograph: HPLC DX-500 with gradient pump

>Analytical column:

ICE AS1

>Eluent:

heptafluorobutyric acid

Other anions such as $\mathrm{CO}_{3}{ }^{2-}$ are analyzed by standard titration methods. Those results are not discussed here.

\section{Gases}

During each 20-minutes treatment, gas samples drawn off before the scrubber entrance (see \#15-gas to scrubber on Figure 2) after various time intervals: 7 and 20 minutes. The gas analysis performed is not exhaustive, being limited to the qualitative identification of the most probable "sulphurated" gaseous products: $\mathrm{SO}_{2}(\mathrm{~g})$ and $\mathrm{H}_{2} \mathrm{~S}(\mathrm{~g})$. Gaseous samples are analyzed by gas chromatography using a calibration curve for both compounds, using the following listed equipment and operating conditions:

- $\mathrm{SO}_{2}(\mathrm{~g})$ and $\mathrm{H}_{2} \mathrm{~S}(\mathrm{~g})$

$>$ Gas Chromatograph: CP-3800 Varian chromatograph

>Analytical column: Porapack QS Teflon

>Detector: Thermal conductivity (TCD)

>Column temperature: $135^{\circ} \mathrm{C}$

>Carrier gas: Helium

\section{Experiments}

The experiments, described in Table 2, are part of a partial factorial analysis $2^{4-1}$. The tests having a catalyst concentration equal to the reference catalyst concentration $(02,03,04$ and 08 ) are aimed at the identification of two of the severity factor model parameters: the rate constant $k_{\text {Tref }} \mathrm{Cref}_{\text {f }}$ and the parameter $\gamma$. These parameters are determined for the kinetics

Table 2. Experiments of the factorial $2^{4-1}$ to evaluate the parameters $k_{\text {Tref, Cref }}$ and $\gamma$.

\begin{tabular}{lcccc}
\hline Test \# & Plasma Gas & $\begin{array}{c}\mathrm{Na}_{2} \mathrm{~S} \\
(\mathrm{~mol} / \mathrm{L})\end{array}$ & $\begin{array}{c}\text { Organic Acids } \\
(\mathrm{mol} / \mathrm{L})\end{array}$ & $\begin{array}{c}\text { Catalyst } \\
(\mathrm{ml} / \mathrm{L})\end{array}$ \\
\hline 01 & Air & 0.07 & 0.21 & 0 \\
02 & $\mathrm{O}_{2}$ & 0.07 & 0.21 & 0.033 \\
03 & Air & 0.07 & 0.42 & 0.033 \\
04 & Air & 0.14 & 0.21 & 0.033 \\
05 & $\mathrm{O}_{2}$ & 0.14 & 0.21 & 0 \\
06 & $\mathrm{O}_{2}$ & 0.07 & 0.42 & 0 \\
07 & Air & 0.14 & 0.42 & 0 \\
08 & $\mathrm{O}_{2}$ & 0.14 & 0.42 & 0.033 \\
\hline
\end{tabular}

Table 3. Additional experiments to evaluate the reaction order for the catalyst.

\begin{tabular}{lcccc}
\hline Test \# & Plasma Gas & $\begin{array}{c}\mathrm{Na}_{2} \mathrm{~S} \\
(\mathrm{~mol} / \mathrm{L})\end{array}$ & $\begin{array}{c}\text { Organic Acids } \\
(\mathrm{mol} / \mathrm{L})\end{array}$ & $\begin{array}{c}\text { Catalyst } \\
(\mathrm{ml} / \mathrm{L})\end{array}$ \\
\hline 03cat1 & Air & 0.07 & 0.42 & 0.017 \\
03 cat2 & & & 0.067 \\
\hline
\end{tabular}


Table 4. Kinetic parameters $k_{\text {Tret Cref }}$ and $\gamma$ obtained for formic acid decomposition.

\begin{tabular}{lcccc}
\hline & \multicolumn{2}{c}{ Parameter } & & $\begin{array}{c}\text { Regression } \\
\text { Coefficient }\end{array}$ \\
\cline { 2 - 3 } Test \# & $k_{\text {Tref, Cref }}\left(\mathrm{min}^{-1}\right)$ & $\gamma$ & $\mathrm{R}^{2}$ \\
\hline 02 & $1.59 \mathrm{E}-05$ & 0.8093 & 0.957 \\
03 & $7.47 \mathrm{E}-06$ & 0.8916 & 0.985 \\
04 & $2.64 \mathrm{E}-05$ & 0.3537 & \\
08 & $1.03 \mathrm{E}-05$ & 1.050 & 0.831 \\
Mean & $1.50 \mathrm{E}-05$ & & \\
& & & \\
\hline
\end{tabular}

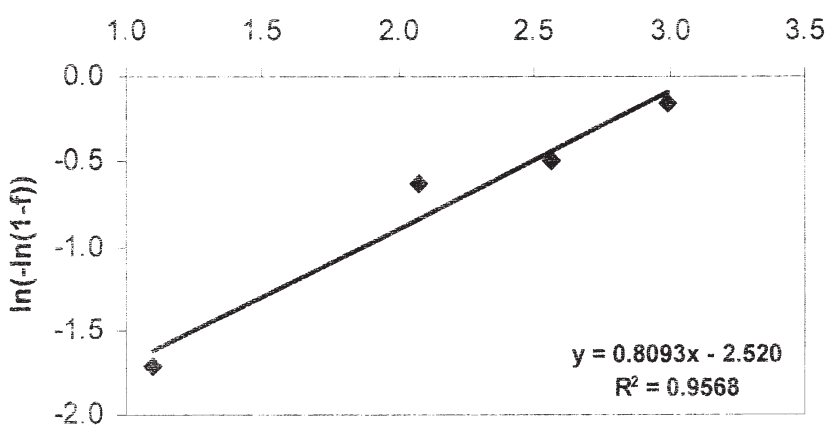

$\ln (\mathrm{t})$

Figure 3. Plot of experimental results to calculate model's parameters $\gamma$ and $k_{\text {Tret, Cret }}$.

Table 5. Kinetic parameters $\gamma$ obtained for formic acid decomposition with different plasma gas.

\begin{tabular}{lccc}
\hline & \multirow{2}{*}{$\mathrm{O}_{2}$ Plasma gas } & & \multicolumn{2}{c}{ Air Plasma Gas } \\
\cline { 2 - 2 } Test \# & $\gamma$ & Test \# & $\gamma$ \\
\hline 01 & 0.3420 & 02 & 0.8093 \\
03 & 0.8916 & 05 & 0.9971 \\
04 & 0.3537 & 06 & 0.8551 \\
07 & 0.2139 & 08 & 1.050 \\
\hline
\end{tabular}

of formic acid decomposition and of sulfur oxidation; these parameters being calculated by means of Equations (9) and (10) previously developed. Other tests of the factorial analysis were not used for the kinetic study of the process.

To determine the value of the third parameter of the severity factor model, the parameter $m$, which is the reaction order for the catalyst, the experiments described in Table 3 are performed in addition to the factorial analysis experiments. Through knowledge of the parameters $k_{\text {Tret, Cref }}$ and $\gamma$ from the previous experimental data processing, it is then possible to calculate the reaction order for the catalyst by means of Equations (13) and (14).

\section{Results and Discussion \\ Evaluation of Parameter $k_{\text {Tref, } C r e f}$ and $\gamma$ Formic Acid Decomposition}

Each of the kinetic parameters $k_{\text {Tref,Cref }}$ and $\gamma$, obtained through the use of Equations (9) and (10) for decomposition
Table 6. Kinetic parameters $k_{\text {tref } c \text { ref }}$ and $\gamma$ obtained for sulfur oxidation.

\begin{tabular}{|c|c|c|c|}
\hline \multirow[b]{3}{*}{ Test \# } & & & \multirow{3}{*}{$\begin{array}{c}\text { Regression } \\
\text { Coefficient } \\
\mathrm{R}^{2}\end{array}$} \\
\hline & \multicolumn{2}{|c|}{ Parameter } & \\
\hline & $k_{\text {Tref, Cref }}\left(\mathrm{min}^{-1}\right)$ & $\gamma$ & \\
\hline 02 & 4.17E-05 & 0.6914 & 0.9998 \\
\hline 03 & $2.92 \mathrm{E}-05$ & 0.3583 & 0.9996 \\
\hline 04 & $3.33 \mathrm{E}-05$ & 0.3104 & 0.9693 \\
\hline 08 & $2.84 \mathrm{E}-05$ & 0.3895 & 0.9993 \\
\hline Mean & $3.32 \mathrm{E}-05$ & 0.4374 & \\
\hline
\end{tabular}

of formic acid, is summarized in Table 4. An example of the calculations performed to obtain these parameters is given here for the test 02 .

The experimental results of conversion are plotted as a function of the logarithm value of time using Equation (9) and the specified values of $\omega$ and $T_{\text {ref }}$ :

$\ln (-\ln (1-f))=\ln \left(\frac{k_{\text {Tref, Cref }}}{\gamma} \exp \left(\frac{T-298}{14.4}\right)\right)+\gamma \ln t$

The obtained curve is presented in Figure 3. The regression curve fits the data with a coefficient $\mathrm{R}^{2}$ of 0.96 . The slope of the curve, 0.8093 , gives the value of the parameter $\gamma$. Knowing this value, it is possible to use Equation (10) with the same specified values of $\omega$ and $T_{\text {ref }}$ the calculated parameter $\gamma$ and the intercept of the curve, to calculate the reference rate constant:

$$
\begin{aligned}
k_{\text {Tref }, \text { Cref }} & =0.8093 \exp \left[-2.520-\frac{T-298}{14.4}\right] \\
& =1.59-10^{-5}
\end{aligned}
$$

The obtained mean parameter $k_{\text {Tref,Cref }}$ is $1.50 \times 10^{-5} \mathrm{~min}^{-1}$ and no significant variation is observed with changes to the operating conditions of the factorial analysis.

On the other hand, the parameter $\gamma$ of Table 4 seems to be quite variable with respect to operating conditions: 0.3537 to 1.050. Analysis of the gamma parameter obtained from each experiment of the factorial analysis, presented in Table 5 , indicates that the variation of $\gamma$ is statistically significant. In fact it has been statistically verified, that although variations exist within a group of tests using the same plasma gas under different operating conditions, plasma gas type only is having a significant influence on this $\gamma$ parameter (Yargeau, 2002).

The variation of this $\gamma$ parameter with respect to plasma gas type might be explained by the properties of the plasma and the radicals formed. With oxygen as the plasma gas, the overall plasma temperature is higher due to the lower dissociation energy of oxygen and there are more free radicals that contribute to the degradation of the organics in solution. With air as the plasma gas, plasma temperature is lower and free radicals are also involved in reactions, others than organic decomposition reactions, to form nitrogen-based compounds. As a result of the formation of nitrogen-based compounds, the $\mathrm{pH}$ is lowered which involves a decrease of organic acid 
Table 7. Experiment to verify the variation of $\gamma$ with pressure.

\begin{tabular}{lcccc}
\hline Test \# & Plasma Gas & $\begin{array}{c}\mathrm{Na}_{2} \mathrm{~S} \\
(\mathrm{~mol} / \mathrm{L})\end{array}$ & $\begin{array}{c}\text { Organic Acids } \\
(\mathrm{mol} / \mathrm{L})\end{array}$ & $\begin{array}{c}\text { Catalyst } \\
(\mathrm{mL})\end{array}$ \\
\hline 03Pd & Air & 0.07 & 0.42 & 0.033 \\
\hline
\end{tabular}

Table 8. Parameters $\gamma$ for tests at different pressures.

\begin{tabular}{lcccc}
\hline Test \# & Pressure $(\mathrm{kPa})$ & Temperature $\left({ }^{\circ} \mathrm{C}\right)$ & $\begin{array}{c}\gamma \text { obtained for } \\
\text { formic acid decomposition }\end{array}$ & $\begin{array}{c}\gamma \text { obtained for } \\
\text { sulfur oxydation }\end{array}$ \\
\hline 03 & 445 & 145 & 0.8916 & 0.3583 \\
$03 \mathrm{C}$ & 445 & 145 & 0.8491 & 0.3488 \\
$03 \mathrm{Pd}$ & 585 & 153 & 0.5041 & 0.7408 \\
\hline
\end{tabular}

decomposition (Sano et al., 2001). The reaction mechanism is thus different due to the radicals formed with air compared to oxygen as a plasma gas and this can explain the difference obtained in the gamma parameter.

The variation of the $\gamma$ parameter with respect to temperature is discussed in the section Variability of $\gamma$ with temperature.

\section{Sulfur Oxidation}

Each of the kinetic parameters $k_{\text {Tref } C r e f}$ and $\gamma$, obtained through the use of equations (9) and (10) for sulfur oxidation, are summarized in Table 6. By the same procedure as the analysis of the results for the decomposition of formic acid, the mean parameter $k_{\text {Tref,Cref }}$ obtained is $3.32 \mathrm{E}-05 \mathrm{~min}^{-1}$ and the mean parameter $\gamma$ is 0.4374 . The dependence of both parameters on the operating conditions is not statistically significant for sulfur oxidation (Yargeau, 2002), the mechanism of which is probably less sensitive to changes in the plasma properties.

As for the decomposition of formic acid, the variation of the $\gamma$ parameter with respect to temperature is analyzed in the following section Variability of $\gamma$ with temperature.

\section{Variability of $\gamma$ with Temperature}

To analyze the variability of the parameter $\gamma$ with temperature, experimental data should be obtained at different reaction temperatures and analyzed to obtained kinetic parameters that can be compared to previous results. Interactions between operating conditions are quite complex in the submerged plasma system, in fact, variation of temperature alone is impossible to obtain. This variation involves a pressure change that causes other modifications such as reaction volume changes and flow pattern changes as discussed in (Quintal, 2002).

To evaluate if a pressure change, with its various impacts on the system, influences the $\gamma$ parameter, one more test, as described in Table 7, was performed under a higher pressure. The results obtained at this elevated pressure through the use of Equations (9) and (10) for sulfur oxidation and for formic acid decomposition are presented in Table 8.

To determine if the difference in $\gamma$ is significant or not, predicted concentrations from the model using a mean value of $\gamma$ and predicted concentrations of the model using the value of $\gamma$ at the pressure corresponding to the experimental data pressure are compared to the experimental results. Figure 4 shows that the variation is significant for formic acid decompo-

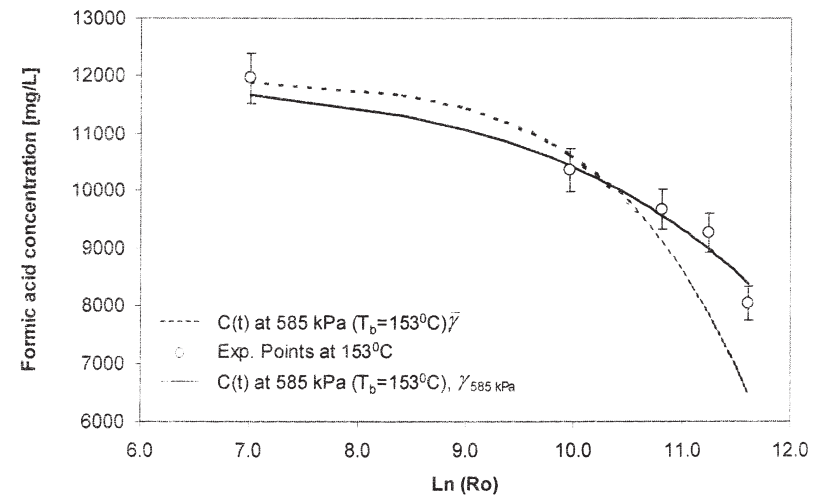

Figure 4. Significance of variability of $\gamma$ with pressure for formic acid decomposition.

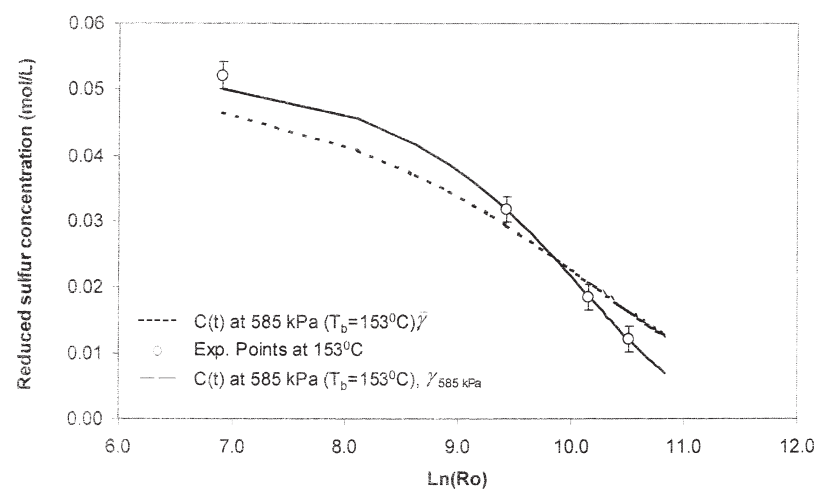

Figure 5. Significance of variability of $\gamma$ with pressure for sulfur oxidation.

sition: The predicted concentration profile, based on the mean value of $\gamma$, does not fit the experimental data. Figure 5 demonstrates the same phenomenon for sulfur oxidation and indicates clearly that the variation of $\gamma$ with respect to pressure has a significant influence on the model's predictions.

\section{Evaluation of Parameter $m$ Formic Acid Decomposition}

The calculation of the reaction order for the catalyst, using Equations (13) and (14), is summarized in Table 9. An example 
Table 9. Calculation of the reaction order for the catalyst in formic acid decomposition.

\begin{tabular}{lccccc}
\hline & & \multicolumn{2}{c}{ Obtained From Eq (13) and (14) } & & \multicolumn{2}{c}{ Regression Coefficient } \\
\cline { 3 - 4 } Test \# & Catalyst $(\mathrm{mL})$ & Intercept b & $\gamma$ & $\mathrm{R}^{2}$ & 0.915 \\
\hline 03cat1 & 0.017 & -3.851 & 0.123 & 0.990 & 0.3 \\
03cat2 & 0.067 & -2.317 & 0.6779 & & Mean \\
& & & & 0.85 \\
\hline
\end{tabular}

Table 10. Calculation of the reaction order for the catalyst in sulfur oxidation.

\begin{tabular}{|c|c|c|c|c|c|}
\hline Test \# & Catalyst (mL) & \multicolumn{2}{|c|}{ Obtained From Eq (13) and (14) } & $\frac{\text { Regression Coefficient }}{\mathrm{R}^{2}}$ & Order m \\
\hline 03cat1 & 0.017 & -0.513 & 0.252 & 0.978 & -0.066 \\
\hline \multirow[t]{2}{*}{03 cat2 } & 0.067 & -0.828 & 0.358 & 0.969 & 0.071 \\
\hline & & & & Mean & 0.002 \\
\hline
\end{tabular}

of the calculations performed to obtain these parameters is given here for the test 03 cat 1 .

The experimental results of conversion are plotted as a function of the logarithm value of time using Equation (13), the specified values of $\omega$ and $T_{\text {ref }}$ the value $k_{\text {Tref }}$ Cref $f^{\prime}=1.13 \times 10^{-5}$ obtained for a test with the same conditions except that $C=$ $C_{\text {ref }}$ and the obtained value $\gamma=1.123$ :

$\ln (-\ln (1-f))=\ln \left(\begin{array}{c}\frac{1.13 \times 10^{-5}}{1.23} \\ \exp \left(\frac{T-298}{14.4}\right) \\ \exp \left(\frac{m(C-0.033)}{0.033}\right)\end{array}\right)+1.123 \ln (t)$

The intercept $b$ of this plot, presented in Figure 6 , is used in Equation (14) to evaluate the reaction order for the catalyst:

$m=\frac{0.033 \cdot\left[\begin{array}{l}14.4 \cdot\left(\ln 1.123-\ln 1.13 \times 10^{-5}\right) \\ +(14.4) \cdot(-3.851)+298-418\end{array}\right]}{14.4(0.017-0.033)}=1.3$

The obtained mean reaction order value of 0.85 is validated by the Figure 7 : If the reaction order for the catalyst is neglected, the model does not fit the experimental data.

\section{Sulfur oxidation}

The calculation of the reaction order for the catalyst, using Equations (13) and (14), is summarized in Table 10. The value obtained is quite close to zero. From this result, it seems that the oxidation of sulfur is not catalyzed. This conclusion is also statistically validated by the results of the factorial analysis (Yargeau, 2002).

\section{Validation of the Model}

Figure 8 demonstrates the adequacy of the model for the prediction of formic acid decomposition and also for sulfur

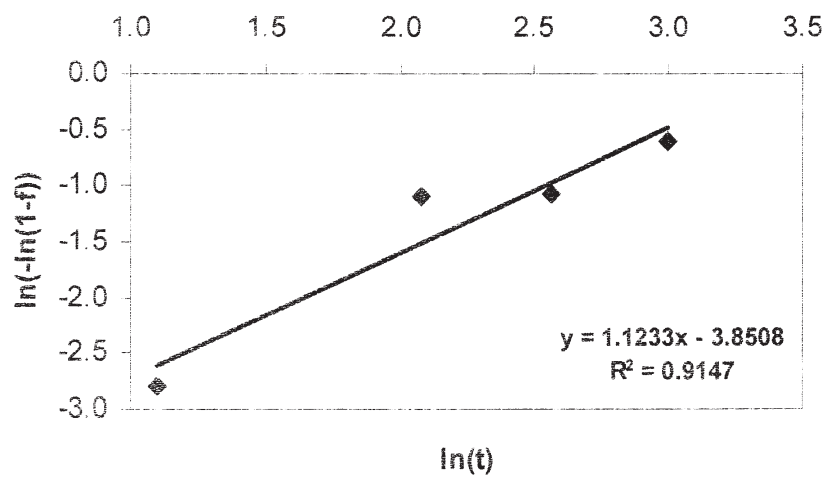

Figure 6. Plot of experimental results to calculate model's parameter $m$.

oxidation in the submerged plasma treatment of black liquor. The information so obtained can then be used to optimize the conventional thermal treatment or to design new ways of thermal treatment.

It is thus now possible to write the following equations for the prediction of formic acid decomposition and sulfur oxidation as a function of catalyst concentration, temperature and time interval of the treatment. However, it must be noted that the parameter $\gamma=0.92$ for formic acid decomposition is not constant for the entire range of operating conditions. This value of gamma, and thence Equation (19), is adequate when $\mathrm{O}_{2}$ is used as a plasma gas and for only a limited pressure range. Further experiments need to be performed to optimize the use of this parameter.

$$
\begin{aligned}
\ln \left(1-f_{\text {formic }}\right) & =-1.50 E-05\left(\frac{C}{0.033}\right)^{0.85} \\
& \exp \left(\frac{T-298}{14.43}\right) \frac{t^{0.92}}{0.92} \\
\ln \left(1-f_{\text {sulfur }}\right) & =-3.32 \times 10^{-5} \exp \left(\frac{T-298}{14.43}\right) \frac{t^{0.44}}{0.44}
\end{aligned}
$$




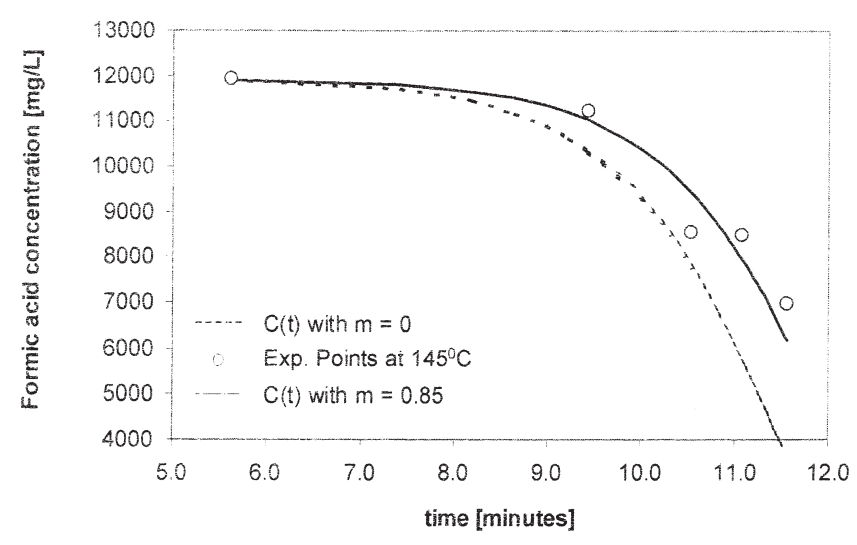

Figure 7. Validation of the reaction order for the catalyst in formic acid decomposition.

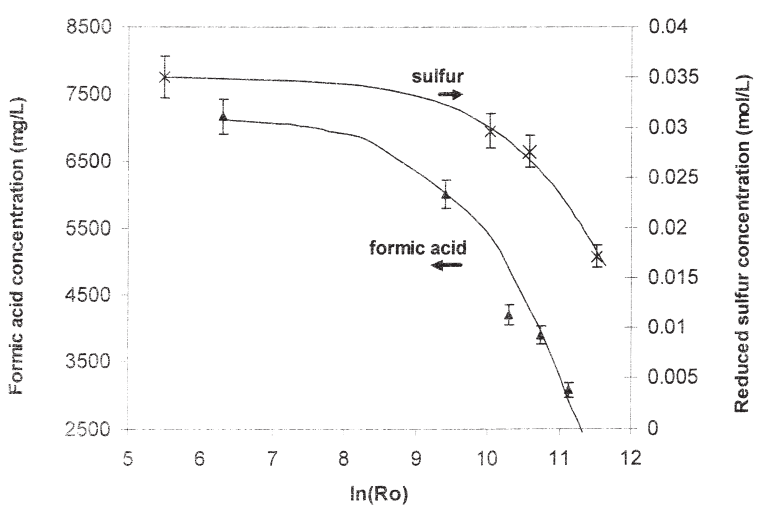

Figure 8. Model validation for oxidation of sulfur and decomposition of formic acid.

\section{Conclusion}

This paper reports innovative results demonstrating that the phenomenological severity factor kinetic model, developed for the decomposition of cellulose, is also adequate to predict the kinetic behavior of complex systems such as those formed during the thermal treatment of black liquor. This model can then be used to optimize the conventional treatment of black liquor or the novel submerged plasma treatment, described in the experimental set-up section. However, the results obtained in this work indicate that the severity factor kinetic model might be more efficient through the optimization of the gamma parameter to adapt the model to the more homogeneous molecular composition of the black liquor. The development and validation of this kinetic model will be evaluated in further work and subsequently applied to black liquor lignin decomposition kinetic. Improvement of characterization techniques will also be required for this next research stage.

\section{Acknowledgements}

Grateful acknowledgements are made to the Natural Sciences and Engineering Research Council of Canada (NSERC: Postgraduate Scholarship and Collaborative Research and Development Grants (CRD) with Alcan International Ltd) and the Fonds pour la formation de chercheurs et I'aide à la recherche (FCAR Funds: Postgraduate Scholarship) for their financial support. The analysis assistance of Domtar Inc. is also gratefully acknowledged.

\section{Nomenclature}

C catalyst concentration, $\left(\mathrm{mL}^{-1}\right)$

$C_{\text {ref }} \quad$ reference catalyst concentration, $\left(\mathrm{mL}^{-1}\right)$

$E$ activation energy in the Arrhenius equation, $\left(\mathrm{kJ} \cdot \mathrm{mol}^{-1}\right)$

$f \quad$ conversion

$k_{\text {Tret, Cref }}$ rate constant at $T_{\text {ret }}$ and $C_{\text {refr }}\left(\mathrm{min}^{-1}\right)$

$m$ reaction order for the catalyst

$R_{0} \quad$ the severity factor

$r_{i} \quad$ reaction rate at temperature $T,\left(\mathrm{~mol} \cdot \mathrm{min}^{-1}\right)$

$t$ time, (min)

$\mathrm{T}$ temperature, $(\mathrm{K})$

$T_{\text {ref }} \quad$ reference temperature, $(\mathrm{K})$

\section{Greek Symbols}

$\gamma \quad$ parameter defining the shape of the Kohlrausch relaxation function, which also defines the shape of the activation energies distribution

$\bar{\gamma} \quad$ mean parameter

$\omega \quad$ parameter expressing the averaged influence of temperature on the reaction rate $(K)$

$\omega_{0} \quad$ parameter expressing the energetics of the process in respect of a reference reaction temperature

\section{References}

Abatzoglou, N., E. Chornet, K. Belkacemi and R.P. Overend, "Phenomenological Kinetics of Complex Systems: The Development of a Generalized Severity Parameter and Its Application to Lignocellulosics Fractionation", Chem. Eng. Sci. 47, 1109-1122 (1992).

Brasch, D.J. and K.W. Free, "Prehydrolysis-Kraft Pulping of Pinus Radiata Grown in New Zeland", Tappi J. 48, 245-248 (1965).

Cusack, R.W., "A Fresh Look at Reaction Engineering", Chem. Eng., 134-146 (1999).

Fortin, L., G. Soucy, V.K. Kasireddy and J.-L. BERNIER, "Novel Reactor for Cyanide Solution Treatment", Can. J. Chem. Eng., 78, 643-649 (2000).

Geniesse, J.C. and R. Reuter, "Effect of Time and Temperature on the Cracking of Oils", Ind. Eng. Chem. 22, 1274-1279 (1930).

Montané, D., R.P. Overend and E. Chornet, "Kinetic Models for NonHomogeneous Complex Systems with a Time-Dependent Rate Constant", Can. J. Chem. Eng. 76, 58-68 (1998).

Quintal, P., "Étude de l'hydrodynamique d'un réacteur à plasma submergé", Master's thesis, Université de Sherbrooke, Sherbrooke, QC (2002).

Sano, N., T. Kanki and A. Toyoda, "Water Purification by Direct Contact of Corona Discharge", in "Proc. 15 th Int. Symp. on Plasma Chem.", GREMI, CNRS/University of Orléans, France, July 9-13 (2001), pp. 2065-2071.

Westbrooke, C.K. and F.L. Dryer, "Chemical Kinetic Modeling of Hydrocarbon Combustion", Prog. Energy Combustion Science 10, 1-57 (1984).

Whitehurst, D.D., T.O. Mitchell and M. Farcasiu, "Coal Liquefaction: The Chemistry and Technology of Thermal Processes", Academic Press, NewYork, NY (1980).

Yargeau, V., B. Marcos and G. Soucy, "Black Liquor Treatment by Thermal Plasma", in "Proc. $15^{\text {th }}$ Int. Symp. on Plasma Chem.", GREMI, CNRS/University of Orléans, France, July 9-13 (2001), pp. 2987-2992.

Yargeau, V., "Étude du traitement thermique par plasma submergé d'une solution caustique du type liqueur noire", Ph.D. thesis, Université de Sherbrooke, Sherbrooke, QC (2002).

Manuscript received October 3, 2003; revised manuscript received July 6, 2004; accepted for publication November 4, 2004. 